\title{
Study on Legislation of Green Packaging in China
}

\author{
Zhaohui Chen $^{\mathrm{a}}$, Lei Wei ${ }^{\mathrm{b}}$, Lina Ye
}

School of Law and Economy, Bohai University, Jinzhou, 121013, China

ahui4179@aliyun.com, b913238595@qq.com, 'cfeixue9341@163.com

\section{Keywords: green packaging; circular economy; WTO/TBT; WTO/SPS}

\begin{abstract}
Green packaging legislation takes a great place in the protection of environment, it has attracted wide attention in the international community, and has become one of the green barriers of developed countries. Notably, WTO has showed great concern on it and meanwhile lots of developed countries have done a great job in accelerating the development in green packing legislation and eliminating its negative influence. Being one of the WTO members, China has the necessity to carry out the green packaging legislation. The legislation practice of the developed countries also provides a good reference for our country, and we will talk about the suggestions in this passage to construct the green packaging legal system from two aspects: general introduction of green packaging and establishment of comprehensive supporting system.
\end{abstract}

\section{Introduction}

In our daily life, packaging is an indispensable part of a commodity. With the development of logistics and improvement of people's quality of life, green packaging gradually come into people's sight. Green packaging, as maybe defined, refers to saving resources, reducing waste during the product packaging, biological-friendly reuse and recycle, which means no more pollution to the environment [1]. This packaging progress includes the selection of raw materials, production, appliance, recycling of the waste, all of these must comply with environmental protection requirements.

\section{Background}

From the domestic level, with the economic development, people's living condition has leveled up, along with which comes the mania for treasure, luxury, wicked consumption concept and over packaging. In China, for example, paper packaging and bark packaging exacerbated the consumption of China's forest resources; then plastic bags, always be the first choice in daily life, have resulted in tremendous consumption in China annually. It's hard to deny that plastic shopping bags do provide convenience for consumers, at the same time, due to excessive use and problematic disposal, it caused a serious waste of energy resources and environmental contamination. In particular, ultra-thin plastic shopping bags, which are too fragile to be used, they become the elementary ingredients of "white pollution", which goes against environment-friendly" society policy.

From the perspective of international trade, The negative impact on the environment caused by packaging, mainly lies in packaging materials and packaging waste as well as packaging instruments, they can introduce hidden insects disaster such as borers, bollworm and nematodes into exotic land, which may endanger the ecological environment and local forests and crops; besides that, the newly developed chemical synthetic materials, such as Pvc plastic, is difficult to degrade in a natural way and traditional burning can help with nothing but pollute the air[2].

Because of this, the concept of green packaging came into reality, caused a strong reaction in the domestic and international community. In 1987, the United Nations World Commission on Environment and Development called for the use of green packaging in "Our Common Future", and many developed countries have taken steps to enact packaging laws and directives that contain clear environmental measures for mandatory product recycling and packaging. We will introduce the symbolic two. 


\section{External Legislations}

(1) German. Germany is the first country to carry out green packaging special legislation. The <German Packaging Waste Disposal Act>, adopted in 1991, says, manufacturers and sellers of packaged products should be responsible for the entire life cycle of the product, they also have the obligation to recycle and process the wastes produced by their products ,including the recycling of all kinds of packaging. They should also cover the costs. There exists a principle called "who produces who recycling", "who sells who recycling" between producers and sellers, obeyed by all of them. If someone responsible for recycling, they can mandate "Green Point" Recycling company to do the job. The Packaging Recycling Act specify a qualification of 80 percentage and requires that 80 to 90 per cent of this total must be recycled. For those contaminate environment, the government can charge them with product disposal fees and packaging tax. Germany's green packaging legislation forming an industrial chain through the recycling requirements, utilization, disposal, production, transaction, consumption and the recycling ,the disposal covers all aspects of the decomposition, which is quite operative for all beverages, detergents and paint containers are applicable. At present, Germany has formed a full participation in the green packaging system innovation, "At present, most of the logistics group in Germany and some service companies are actively developing 'ecological logistics concept' in which to reduce carbon dioxide and other greenhouse gas emissions. During the delivery, in order to strictly implement environmental laws and regulations of packaging and waste disposal, they encouraged the use of durable and environmental- friendly container equipment, prohibited the use of those pallets and packaging materials that easily lead to environmental pollution [3].

(2) Japan. Japan has the most sound laws and regulations to promote the development of circular economy among the developed countries, it promulgated the "Packaging Container Recycling Law" in 1995, and made it compulsory to recycle and reuse the package, it also suggested the establishment of containers and packaging recycling system, stipulated that different subjects should assume different responsibilities, even developed specific provisions on the glass bottles, PET bottles, paper products, plastic packaging products. Since April 1997, glass bottles and plastic bottles are recycled by manufacturing companies, and the obligation is limited to large-scale production enterprises. However, among all the wastes, families can generate about $60 \%$ of the volume, container packaging waste accounts for $25 \%$ of the weight. In order to reduce and reuse such wastes, the obligation range has been extended to small and medium-sized enterprises since April 2000. Containers and packaging recycling system involves different subjects and different responsibilities: considered consumers are the main cause of emission, they should bear the duty through reduction in usage, reasonable choices and smart classification of discharge to decrease container packaging waste. Meanwhile, enterprise has the regeneration utilization duty because they are the packaging producers and users. The responsibility of recycling can also be entrusted through payment, the responsibility entrusted to the designated unit and all waste will be dealt in a proper way. After the enforcement of this law, the amount of recycled packaging containers and re-utilization rate of each year were on the rise. Recycling rate of wastes such as aluminum cans increased from $49.2 \%$ in 1986 to $80.6 \%$ in 2000, and the recycling rate of waste from iron cans increased from 58\% in 1986 to $82.9 \%$ in 1999. This shows that the law on reuse has achieved some effects[4].

\section{Comments on the Legislation of Foreign Green Packaging Legislation}

(1) Green Packaging Legislation Become the Mainstream. Their legislative practice generally includes the establishment of green packaging legal system, that is, discreet choice of packaging materials and perfect recycling system. These legal provisions include two aspects, on the one hand, such as encouraging the use of recyclable or recycled packaging materials; set up and complete the green packaging signs system; construct and improve the packaging of the tax system. On the other hand, which can be called the negative list, includes rules such as the prohibition or restriction of using some packaging materials, like PVC-made packaging materials, non-renewable or 
non-degradable plastic packaging, etc [5]. To a certain extent, these countries have reduced the amount of packaging waste by implementing green packaging policy, and comply with the international trade requirements environmental protection era, somehow enhance their international status in the international market. They not only coordinate with the historical trend of sustainable development, but also meet the needs of green consumption, hence, there exists rationality in prosperous future.

(2) The Opposite Two Sides of Characteristics. Though seemed reasonable at the first glance, the regulations of packaging are a little bit harsh and cumbersome. Importers must comply with these requirements, otherwise they will not be allowed to import or merchandise in the market, which makes these acts essentially functioned as barrier in trade. Manufacturers in developing countries suffered from the lack of knowledge of relevant laws and regulations in foreign countries, transaction failed because commodity packaging cannot satisfy the demanding standard of foreign investors; besides, even these stringent requirements are satisfied, it's inevitable to pay huge testing and evaluation fees, as well as certification application fee, annual charge of the usage of signs.

\section{Necessity of Internal Legislation}

(1) In Need of Developing Circular Economy. Circular economy requires the comprehensive utilization of resources, so that we can make the best use of and minimize the waste of resources, especially those will bring harm to the environment. At present, China's packaging evaluation System is still below the global average, which makes it more severe for the government to take quick action in legislation, in service of the realization of china's circular economy goal.

(2) In Need Of Facilitating Export. China's traditional packaging in export trade repeatedly run up against a stone wall, Europe and the United States and other countries of the environmental regulations have higher requirements on animal and plant quarantine, they ask that the production of some natural materials, packaging must go through health inspection and quarantine to prevent dissemination of pests and diseases. China's packaging have been repeatedly criticized by the importing country and suffered from restrictions for our indifference about the materials, as well as pests and diseases which are brought in by packages made up of wood, straw, etc [6]. Because the absence of related and forcible regulations, China has no choice but to face the huge losses in export trade.

(3) In Protection of Rights and Interests. We must clearly recognize that green packaging legislation is a double-edged sword", although, it will certainly increase the cost of domestic enterprises and reduce their competitiveness abroad in the short term. However, to avoid being taken advantage of not having specific regulations, green packaging legislation can build a green barrier for our country. In short, in international trade chains, green packaging system can not only minimize environmental pollution, protect our ecological environment and people's well-being, but also act as a legitimate non-tariff barriers, which is a an important guarantee to improve the capacity of export [7].

\section{Analysis on Defects and Countermeasure of Chinese Green Packaging System}

\section{(1) Defects}

Tax legislation is one of the major economic incentive for governments to protect the environment. China's tax legislation cannot meet the requirements. This is mainly reflected in two aspects, firstly, China has not applied specific environmental taxes, we are short of guidance on the role of packaging special taxes. Secondly, the relevant provisions of environmental protection scattered in different taxes, consumption tax, value-added tax and other relevant tax provisions, special preferential tax terms need to be deployed in purpose of urgent development in packaging industry. Although the legislation can promote the implementation of green packaging system, but in order to flourish the green packaging industry, legislation is not a panacea. Fundamentally speaking, "green" indicates a high-cost standard of packaging, it needs high-tech support, as well as the need of advanced technology. It has been a long time since the ban of plastic came into implementation, still 
we are unable to find an effective alternative. China's green packaging industry is vulnerable and weak, without the government's positive guidance and policy it can hardly make any achievements.

Frankly speaking, our packaging recycling system is in a mess, there is no practical and independent mechanism of packaging recycling system, the burden of recycling job was rely on the shoulders of scattered workers, whose search region is very limited. As a matter of fact, they are more preferable in paper packaging than those shampoo bottles or glass bottles. Furthermore, from time to time they will be charged by property management company under the name of administration, which seems so unfair.

Last but not least, these companies possess environmental quality certification and use "green" packaging products labels have greater competitiveness compared to those don't. Driven by tempting profit, non-green packaging companies may take the risk in faking, forging and fraudulently using green packaging signs without authority. As a result, on the one hand, green packaging companies' invest in research and development of green packaging cannot be paid off; on the other hand, these deeds gradually weaken the vitality of the market, aggravate loss to such green enterprises.

(2) Countermeasures

The establishment of green packaging tax law will certainly make it more costly in using the materials which is difficult to degrade than those not, considering they will be charged with high fees, which will make the price more acceptable in the market. On the one hand, we can learn from foreign experience in tax legislation on packaging, such as tax on different packaging materials, if the packaging constitutes recyclable elements, it can be tax-free; if partially recyclable, a lower tax is levied; if there are all materials that cannot be recycled or reused, a higher tax is levied. On the other hand, it is advisable to carry out special green packaging preferences in other taxes, such as enterprises who comply with environmental technology standards may enjoy a tax relief in order to encourage the enterprises in purchase of high-tech packaging.

The WTO is actively cooperating with ISO, it also requires members to make national regulations based on international standards. As one of the WTO members, China need active and rigorous implement that covers the international standards of ISO14000, and supervise the entire progress from production process to recycling. Meanwhile, our government may come up with forcible policy and regulations to stimulate industrial innovation and eliminate blocks in their ways.

Propound packaging recycling system is conducive in expanding the scope of waste recycling, as well as securing the legitimate rights and interests of migrant workers engaged in packaging recycling, not mention the promotion of civil recycling industry. China may learn a lesson from Germany's "beverage packaging deposit system", we cannot turn a blind eye to the classification of packaging waste, which must be mastered with proper management and disposal simultaneously. We can also "set up special recycling companies, which operate under commissions and direct instructions; those who entrust the company for recycling, its products should be paste the company's recycling logo, commission processing fee will be charged according to the quantity; those without signs of packaging waste will be skipped, and the enterprise itself is responsible for recycling [8].

We believe that laws and regulations should be used to clarify the responsibility and protect the legitimate rights and interests of green packaging enterprises. In addition to competition law and monopoly law and the provisions of the Patent Law, there should exist another clear legal responsibility for consumers and companies. If we keep an open eye on Japan and Germany, their practice will provide us with a good reference. Considering the fact that our country has always been a government-led-legislation country, we should also bear in mind that the legal responsibility of the Government should be specified as soon as possible, the government need to come up with legal principles in green packaging legislation to clearly defined governments' administration and their corresponding legal responsibilities. 


\section{References}

[1] L. Na, Z. P. He, "WTO and environment protection," Jilin People's Press, p. 56, 2002.

[2] Q. Wang, "Research on Green Barrier in Agricultural Trade: A Vision Based on WTO," Master paper from Southwest University of Political Science and Law, 2005.

[3] Y. J. Li, L. D. Xu, "Green marketing management of enterprises under low carbon economy," Modern Economic Information, vol. 576, no. 10, p. 17, 2010.

[4] M. D. Qi, "Research on Law of Circular Society," China Environmental Science Press, pp. 59-60, 2008.

[5] F. T. Zheng, "A Brief Research on Market Regulations of Ecological Cost Control," Journal of Changsha University, vol. 114,no. 6, pp. 87, 2006.

[6] W. Y. Zhang, "See Development of 'greenlization' in China From the Perspective of International Green Packaging Industry, " The packaging World, vol. 114, no. 1, pp. 26, 2005.

[7] X. Zhang, H. J. Zhang, X. Li "The Legal Countermeasures of Chinese Agricultural Products Export in Green Barrier," Modernization of Market, vol. 840, no. 22, pp. 325, 2007. 